\title{
PENERAPAN MODEL INTEGRASI FUZZY SERVQUAL-IPA-QFD DALAM ANALISIS KUALITAS LAYANAN STASIUN GAMBIR
}

\author{
Ronald Sukwadi $^{*}$, Priskilla Putri Josua ${ }^{2}$, Hendy Tannady ${ }^{3}$ \\ ${ }^{1,2}$ Program Studi Teknik Industri, Universitas Katolik Indonesia Atma Jaya \\ *Email: ronald.sukwadi@atmajaya.ac.id \\ ${ }^{3}$ Program Studi Magister Manajemen, Institut Teknologi dan Bisnis Kalbis \\ Surel: hendy.tannady@kalbis.ac.id
}

Masuk: 15-10-2020, revisi: 24-08-2021, diterima untuk diterbitkan: 05-04-2021

\begin{abstract}
ABSTRAK
Angkutan umum telah dianggap sebagai salah satu bentuk transportasi paling berkelanjutan di Indonesia. Kereta Api Indonesia menjadi salah satu moda transportasi pilihan dan perusahaan transportasi terbesar. Stasiun Gambir adalah stasiun tersibuk di mana banyak orang menghabiskan banyak waktu, menunggu untuk naik kereta, turun dari kereta, keluar/masuk penumpang, atau membeli tiket. Penumpang harus memiliki pengalaman yang memuaskan tentang fasilitas yang tersedia di stasiun, terlepas dari durasi atau tujuan mereka tinggal di stasiun kereta api. Penelitian ini bertujuan untuk menilai tingkat kepuasan penumpang dan meningkatkan kualitas pelayanan stasiun yang ada. Model terintegrasi fuzzy SERVQUAL, IPA dan $Q F D$ diterapkan dalam penelitian ini. Fuzzy SERVQUAL digunakan untuk menilai tingkat kepuasan penumpang. Selanjutnya, Importance Performance Analysis (IPA) digunakan untuk mengetahui atribut-atribut yang harus ditingkatkan. Metode Quality Function Deployment (QFD) digunakan untuk menentukan upaya/strategi yang tepat untuk memperbaiki atribut tersebut. Untuk memenuhi kebutuhan penumpang, Stasiun Gambir harus memasang papan tanda kebersihan, melakukan pelatihan petugas stasiun, dan melakukan penambahan area penghijauan.
\end{abstract}

Kata Kunci: Kualitas layanan, Fuzzy SERVQUAL, IPA, QFD, stasiun kereta api

\section{ABSTRACT}

Public transportation has been regarded as one of the most sustainable forms of transport in Indonesia. Indonesian Railways serves as one of choice transportation mode and the biggest transportation service company. Gambir Central Station is the busiest railway platform where large number of people spend considerable amount of time, while waiting to board a train, alighting from a train, to receivel send off a passenger, or to buy a ticket. The passengers must have a satisfactory experience of the amenities available at platforms, irrespective of their duration or purpose of stay at a railway station. This study aims to assess the satisfaction level of the passengers and to improve the existing service quality of the station. The integrated model of fuzzy SERVQUAL, IPA and QFD is applied in this study. The fuzzy SERVQUAL is used to assess the level of passengers' satisfaction. Furthermore, the Importance Performance Analysis (IPA) method is used to find out the attributes that must be improved. The Quality Function Deployment (QFD) method is used to determine the appropriate efforts/strategies to improve those attributes. To meet the passengers' needs, Gambir Central Station should install a hygiene signboard, conduct training of officers, and add greening areas.

Keywords: Service quality, Fuzzy SERVQUAL, IPA, QFD, Railway station 


\section{PENDAHULUAN}

Untuk menarik pelanggan atau pengguna transportasi, penyedia transportasi termasuk kereta api, harus berusaha sebaik mungkin memberikan layanan terbaik untuk memenuhi kepuasan pengguna jasa transportasi tersebut (Sukwadi et al., 2014; De Ona et al., 2015; Ghosh et al., 2017; Deveci et al., 2019; Ojha, 2020). Dalam konteks yang lebih luas, kepuasan atau ketidakpuasan pelanggan merupakan perbedaan antara harapan dan kinerja yang dirasakan pelanggan tersebut (Parasuraman et al., 1986; Lai \& Chen, 2011; Sukwadi et al., 2012). Salah satu hak penumpang adalah memperoleh kenyamanan, keamanan serta keselamatan dalam menggunakan transportasi publik. Untuk memenuhi kebutuhan tersebut, perusahaan angkutan umum harus dapat menyesuaikan layanan yang mereka berikan kepada pengguna jasa transportasi umum saat ini (Maruvada \& Bellamkonda, 2010; Cascetta \& Carteni, 2014; Deveci et al., 2019; Bakti et al., 2020).

Salah satu alat transportasi publik darat yang banyak diminati adalah kereta api (Liou \& Tsao, 2010; Amstrong \& Preston,2017; Ojha, 2020). PT Kereta Api Indonesia (KAI) merupakan salah satu perusahaan yang bergerak di bidang jasa layanan angkutan darat. Salah satu stasiun utama dari PT Kereta Api Indonesia adalah Stasiun Gambir. Sebagai salah satu stasiun yang berlokasi di daerah DKI Jakarta, Stasiun Gambir merupakan stasiun sibuk baik di hari kerja maupun akhir pekan. Stasiun Gambir dibanjiri orang - orang yang hendak melakukan transit atau perjalanan, terlebih pada saat musim liburan (Ojha, 2020). Berdasarkan hasil wawancara dan observasi awal di lapangan, masih terdapat keluhan dari pengguna stasiun kereta api karena layanan yang diberikan dirasa kurang. Karena Stasiun Gambir merupakan stasiun yang selalu ramai pengunjung setiap harinya maka Stasiun Gambir dituntut untuk memiliki kualitas layanan transportasi yang baik dan memuaskan bagi penumpang.

Penelitian ini akan diawali dengan mengumpulkan data kualitatif hasil wawancara dan observasi awal dan juga hasil review di media sosial (Gambar 1) yang dijadikan acuan untuk penelitian lebih lanjut. Data tersebut kemudian dikelompokan berdasarkan kesamaan kategori dan dipeetimbangkan sebagai masukan dalam menentukan variabel kualitas layanan yang akan diteliti lebih lanjut.

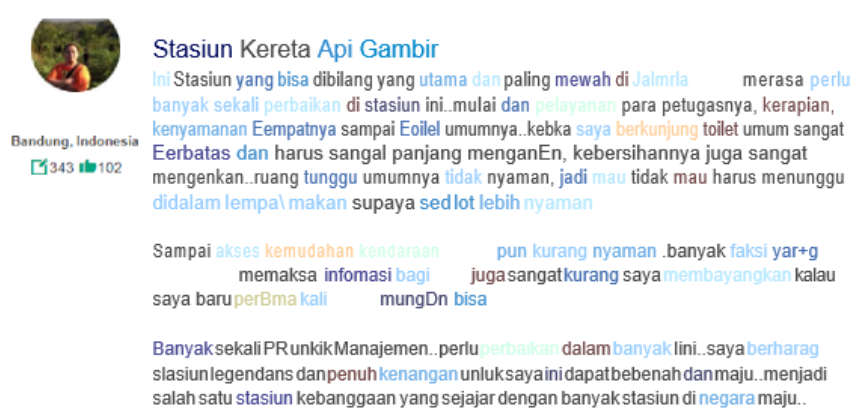

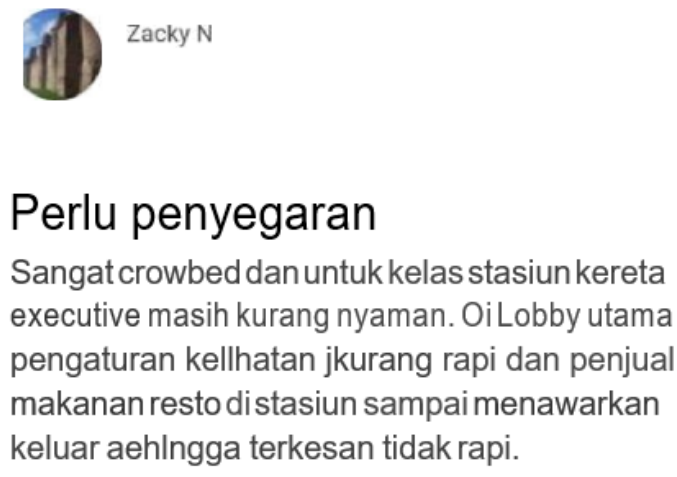

Gambar 1. Contoh keluhan Stasiun Gambir di media sosial

Dari hasil penelitian awal di atas maka perlu dilakukan upaya peningkatan kualitas layanan di Stasiun Gambir. Salah satu alat yang banyak dipergunakan untuk mengukur kualitas layanan yang sudah ada adalah metode SERVQUAL yang diperkenalkan oleh Parasuraman et al. (1986). Dalam penelitian ini, lima dimensi dari SERVQUAL akan dielaborasi lagi dengan penelitian-penelitian sebelumnya yang terkait dengan kualitas layanan di stasiun kereta api seperti penelitian Liou \& Tsao (2010), Maruvada \& Bellamkonda (2010), Lai \& Chen (2011), Cascetta \& Carteni (2014), Sukwadi \& Teofilus (2015), De Ona 
et al. (2015), Ghosh et al.(2017), Amstrong \& Preston (2017), Eboli et al. (2018), Amstrong \& Preston (2017), Devici et al. (2019), Ojha (2020); dan Bakti et al. (2020).

Dalam menilai atribut kualitas digunakan metode fuzzy, di mana metode ini berfungsi untuk menghilangkan nilai yang tidak pasti dari nilai kuesioner (Sukwadi et al., 2014). Fungsi keanggotaan yang digunakan pada metode fuzzy ini adalah Triangular Fuzzy karena memberikan kemudahan dalam suatu perhitungan dan lebih mewakili suatu penilaian. Selanjutnya output fuzzy akan menjadi input pada metode Importance Performance Analysis (IPA) yang dikenalkan oleh Martilla \& James (1977). Metode IPA berfokus pada atribut layanan yang harus diperbaiki pada kuadran I (Sukwadi \& Jufina, 2015; Tannady, 2018; Wilujeng et al., 2019).

Lalu atribut-atribut pada kuadran I tersebut akan menjadi input kebutuhan pelanggan untuk Quality Function Deployment $(Q F D)$. Metode $Q F D$ berfungsi untuk mengembangkan atribut-atribut kualitas layanan dalam rangka memuaskan penumpang kereta api dan kemudian menerjemahkan kebutuhan penumpang tersebut menjadi strategi dan poin utama dalam bisnis kereta api (Akao, 1988). Integrasi ketiga metode tersebut diharapkan dapat digunakan menganalisis kualitas layanan di Stasiun Gambir secara komprehensif. Tujuan dari penelitian ini adalah (1) mengidentifikasi atribut-atribut layanan di Stasiun Gambir; (2) menentukan atribut layanan apa saja yang harus diperbaiki dan ditingkatkan; serta (3) memberikan usulan yang dapat meningkatkan kepuasan penumpang Stasiun Gambir.

\section{METODOLOGI PENELITIAN} Alur Penelitian

Model integrasi fuzzy IPA dan QFD dapat dilihat pada alur penelitian Gambar 2 berikut ini.
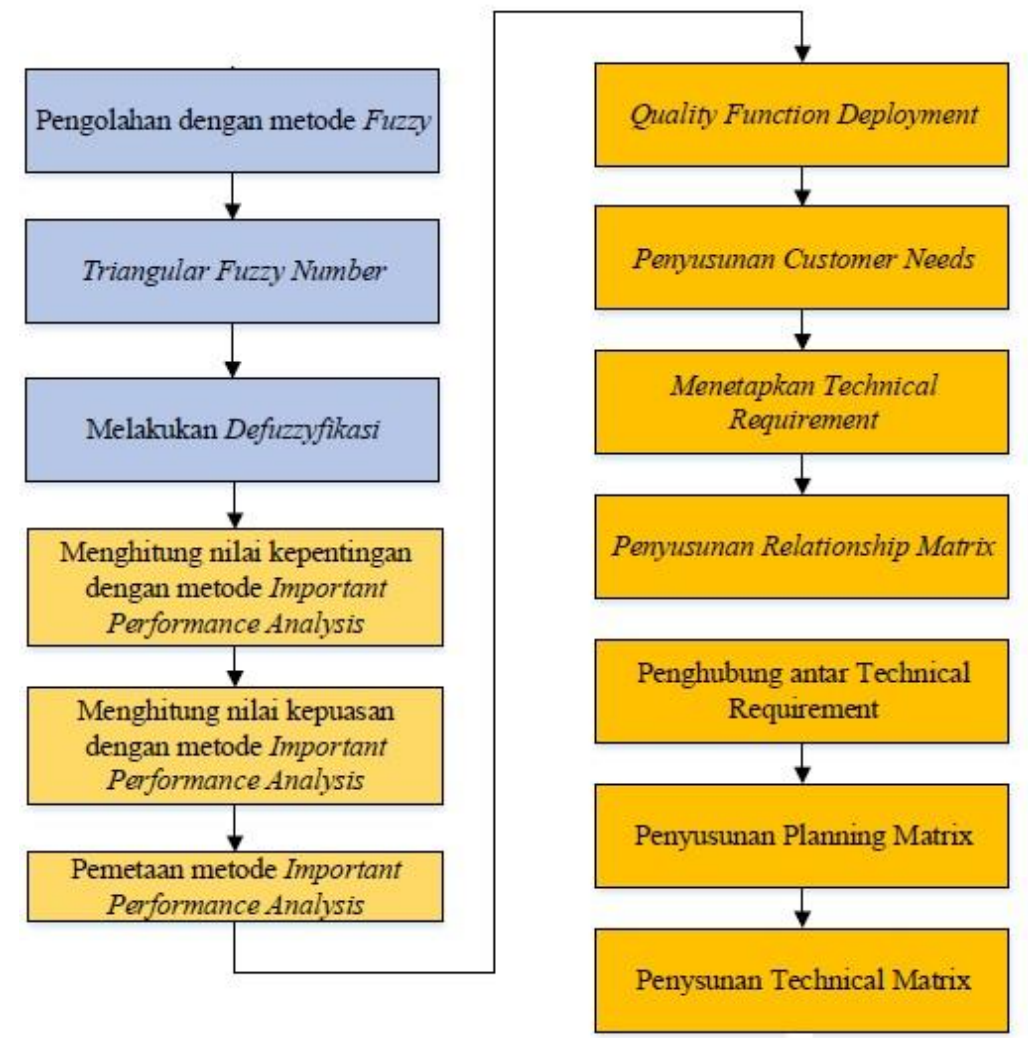

Gambar 2. Alur penelitian 


\section{Desain Penelitian}

Penelitian telah dilakukan pada bulan April-Mei 2019 dengan tempat penelitian di Stasiun Gambir yang berlokasi di Jakarta Pusat. Data yang digunakan untuk penelitian ini bersumber dari data primer dan sekunder. Data primer ini berasal dari kuesioner skala Likert 1 sampai 5 dengan 23 variabel penelitian berdasarkan hasil observasi, dimensi SERVQUAL (Parasuraman et al. 1986), dan penelitian terdahulu (Tabel 1). Kuesioner mengukur tingkat kepentingan, kepuasan dan harapan dari penumpang kereta api. Data sekunder berupa data atau informasi terdahulu baik yang bersumber dari buku, internet, serta jurnal yang relevan dengan penelitian ini. Tabel 1 menyajikan pernyataan atribut layanan yang akan digunakan dalam penelitian ini.

Metode sampling yang digunakan dari non-probability purposive sampling, di mana sampling dilakukan dengan kriteria tertentu yang telah ditetapkan untuk menjadi responden, yakni responden sudah pernah menggunakan jasa Stasiun Gambir. Menurut Hair et al. (2010), jumlah sampel yang dibutuhkan adalah sebesar 5 kali jumlah atribut pertanyaan dalam kuesioner. Dalam penelitian ini jumlah responden melebihi jumlah minimum sampel (115), yaitu sebesar 150 orang.

Tabel 1. Atribut kualitas layanan stasiun

\begin{tabular}{|c|c|c|c|c|c|}
\hline No & Atribut & Sumber & No & Atribut & Sumber \\
\hline 1 & Petunjuk arah di stasiun & \multirow{4}{*}{$\begin{array}{c}\text { Liou \& Tsao } \\
\text { (2010); Lai \& } \\
\text { Chen (2011); } \\
\text { Cascetta \& } \\
\text { Carteni } \\
\text { (2014); } \\
\text { Amstrong \& } \\
\text { Preston (2017) }\end{array}$} & 13 & Fasilitas Disabilitas & \multirow{5}{*}{$\begin{array}{c}\text { Liou \& Tsao (2010); } \\
\text { Maruvada \& } \\
\text { Bellamkonda (2010); } \\
\text { Amstrong \& Preston } \\
\text { (2017); Devici et al. } \\
\text { (2019); Ojha (2020) }\end{array}$} \\
\hline 2 & Jarak parkir ke stasiun & & 14 & $\begin{array}{l}\text { Fasilitas belanja di } \\
\text { restoran dan Cafe }\end{array}$ & \\
\hline 3 & $\begin{array}{l}\text { Akses kendaraan } \\
\text { online/taksi }\end{array}$ & & 15 & $\begin{array}{l}\text { Informasi harga } \\
\text { makanan dan } \\
\text { minuman }\end{array}$ & \\
\hline 4 & $\begin{array}{l}\text { Kejelasan informasi } \\
\text { keberangkatan di layar }\end{array}$ & & 16 & $\begin{array}{l}\text { Keramahan pelayan } \\
\text { outlet }\end{array}$ & \\
\hline 5 & $\begin{array}{l}\text { Kejelasan informasi lewat } \\
\text { pengeras suara }\end{array}$ & \multirow{8}{*}{$\begin{array}{l}\text { Sukwadi \& } \\
\text { Teofilus } \\
\text { (2015); De } \\
\text { Ona et al. } \\
\text { (2015); Ghosh } \\
\text { et al.(2017); } \\
\text { Eboli et al. } \\
\text { (2018); Bakti } \\
\text { et al. (2020) }\end{array}$} & 17 & $\begin{array}{l}\text { Area parkir yang } \\
\text { memadai }\end{array}$ & \\
\hline 6 & $\begin{array}{l}\text { Tempat duduk ruang } \\
\text { tunggu }\end{array}$ & & 18 & Keamanan & \multirow{7}{*}{$\begin{array}{l}\text { Lai \& Chen (2011); } \\
\text { Sukwadi \& Teofilus } \\
\text { (2015); Hundal \& } \\
\text { Kumar (2015); Eboli } \\
\text { et al. (2018) }\end{array}$} \\
\hline 7 & Kebersihan toilet & & 19 & $\begin{array}{l}\text { Sarana keluhan dan } \\
\text { kritik }\end{array}$ & \\
\hline 8 & Kebersiha mushola & & 20 & $\begin{array}{l}\text { Informasi lengkap dan } \\
\text { jelas dari petugas }\end{array}$ & \\
\hline 9 & Media hiburan & & 21 & Kesopanan petugas & \\
\hline 10 & Fasilitas Internet/Wifi & & 22 & Kebersihan stasiun & \\
\hline 11 & Free charging & & 23 & Kesejukan stasiun & \\
\hline 12 & Smoking area & & & & \\
\hline
\end{tabular}

\section{HASIL DAN PEMBAHASAN Demografi Responden}

Demografi responden penelitian ini dapat dilihat di Tabel 2 berikut. 
Tabel 2. Profil responden $(\mathrm{N}=150)$

\begin{tabular}{lc}
\hline \multicolumn{1}{c}{ Karakteristik } & Persentase \\
\hline Jenis Kelamin & \\
Laki-laki & $55 \%$ \\
Perempuan & $45 \%$ \\
\hline Umur & \\
$<$ 20 tahun & $5 \%$ \\
$21-40$ tahun & $79 \%$ \\
$41-50$ tahun & $13 \%$ \\
$>50$ tahun & $3 \%$ \\
\hline Pekerjaaan & \\
Pelajar/Mahasiswa & $17 \%$ \\
Karyawan & $50 \%$ \\
Wirausaha & $23 \%$ \\
Lainnya & $10 \%$ \\
\hline Penghasilan per bulan & \\
$\quad$ < juta & $50 \%$ \\
4-10 juta & $45 \%$ \\
$\quad>10$ juta & $5 \%$ \\
\hline Domisili & \\
Jabodetabek & $88 \%$ \\
Luar Jabodetabek & $12 \%$ \\
\hline
\end{tabular}

Berdasarkan hasil demografi Tabel 2, sebagian besar responden berjenis kelamin laki-laki (55\%), berumur antara 21-40 tahun (79\%), pekerjaan karyawan (50\%), berpenghasilan kurang dari 10 juta rupiah (95\%) dan berdomisili di Jabodetabek (88\%).

\section{Fuzzy SERVQUAL}

Setelah hasil rekapitulasi hasil kuesioner tingkat kepentingan, kepuasan dan harapan didapatkan maka dapat dilakukan perhitungan untuk mengetahui batasan dari masing - masing kriteria yang ada. Setelah didapatkan batasan untuk masing-masing kriteria pada pernyataan kuesioner tingkat kepuasan, kepentingan dan harapan, selanjutnya dilakukan proses defuzifikasi untuk mendapatkan nilai tunggal yang representatif. Perhitungan untuk defuzifikasi dilakukan dengan menggunakan Arithmatic Mean yang diformulasikan sebagai berikut:

$\mu A \cap B=(\mu A x]+\mu B[y]) / 2$

Tabel 3 menyajikan hasil rekap deffuzifikasi pengolahan kuesioner baik untuk tingkat kepentingan, kepuasan dan juga harapan. 
Tabel 3. Hasil defuzifikasi tingkat kepentingan, kepuasan dan harapan

\begin{tabular}{|c|c|c|c|}
\hline \multirow{2}{*}{$\begin{array}{l}\text { No Atribut } \\
\text { Layanan }\end{array}$} & \multicolumn{3}{|c|}{ Hasil Defuzifikasi } \\
\hline & Kepentingan & Kepuasan & Harapan \\
\hline 1 & 10.250 & 8.010 & 10.943 \\
\hline 2 & 9.663 & 7.543 & 10.877 \\
\hline 3 & 9.677 & 10.197 & 10.837 \\
\hline 4 & 9.890 & 7.583 & 10.850 \\
\hline 5 & 9.797 & 6.957 & 10.877 \\
\hline 6 & 9.730 & 6.117 & 10.810 \\
\hline 7 & 9.970 & 7.303 & 10.903 \\
\hline 8 & 9.783 & 8.437 & 10.877 \\
\hline 9 & 9.570 & 7.330 & 10.783 \\
\hline 10 & 9.823 & 5.850 & 10.810 \\
\hline 11 & 9.655 & 6.223 & 10.837 \\
\hline 12 & 9.663 & 8.797 & 10.850 \\
\hline 13 & 9.797 & 8.037 & 10.890 \\
\hline 14 & 9.823 & 7.917 & 10.850 \\
\hline 15 & 9.757 & 5.437 & 10.863 \\
\hline 16 & 9.930 & 9.957 & 10.903 \\
\hline 17 & 9.957 & 7.797 & 10.903 \\
\hline 18 & 10.050 & 8.037 & 10.903 \\
\hline 19 & 9.677 & 7.130 & 10.850 \\
\hline 20 & 9.970 & 7.383 & 10.917 \\
\hline 21 & 9.983 & 7.770 & 10.850 \\
\hline 22 & 9.863 & 6.770 & 10.850 \\
\hline 23 & 10.050 & 7.343 & 10.943 \\
\hline
\end{tabular}

\section{Importance Performance Analysis}

Pada pemetaan diagram IPA, nilai tingkat kinerja/kepuasan dipetakan sebagai sumbu $\mathrm{x}$, sementara nilai tingkat kepentingan dipetakan dengan sumbu $\mathrm{y}$. Pada penelitian ini, batas sumbu $\mathrm{x}$ dan y didapatkan dari hasil defuzifikasi pada metode fuzzy. Hasil diagram dari pengolahan metode Importance Performance Analysis dapat dilihat pada Gambar 4.

Dari diagram IPA tersebut, dapat kita ketahui bahwa terdapat 4 atribut layanan yang berada di kuadran I. Atribut layanan tersebut adalah kebersihan toilet, informasi yang jelas dan lengkap disampaikan petugas, kebersihan stasiun dan kesejukan di stasiun. Keempat output ini akan menjadi input kebutuhan pelanggan bagi metode $Q F D$. 


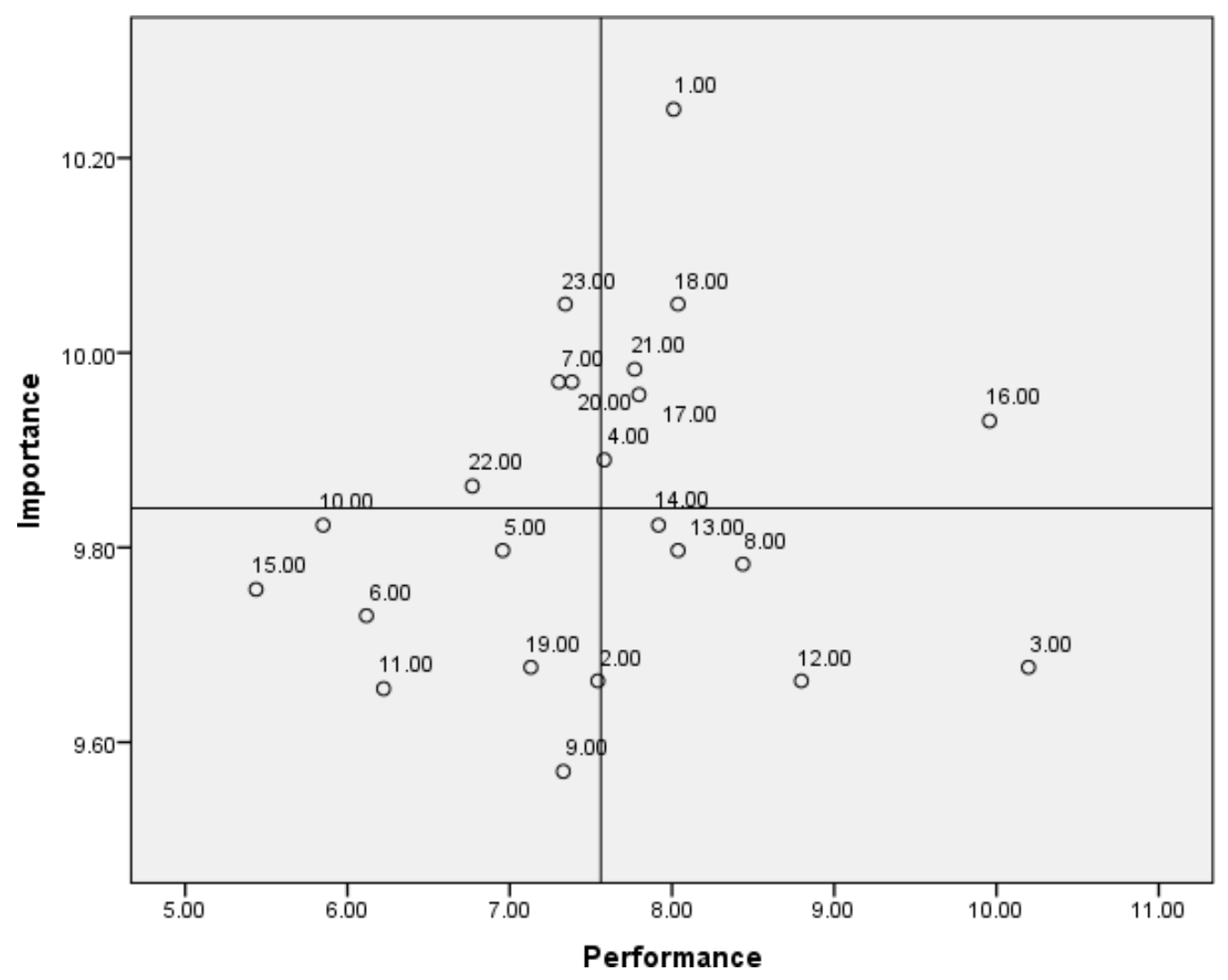

Gambar 4. Diagram pemetaan IPA atribut layanan Stasiun Gambir

\section{Quality Function Deployment}

Pada metode Quality Function Deployment, customer needs didapatkan dari output kuadran I pada metode Importance Performance Analysis, seperti yang telah dijelaskan sebelumnya bahwa atribut yang berada pada kuadran I di metode IPA merupakan atribut yang harus menjadi prioritas untuk diperbaiki karena atribut tersebut memiliki tingkat kepentingan yang tinggi namun kinerjanya belum mampu untuk memuaskan pelanggan.

Penyusunan technical matrix terdiri dari beberapa tahapan yakni perhitungan tingkat kinerja, perhitungan tingkat kepentingan, perhitungan tingkat harapan, perhitungan improvement ratio, penentuan sales point, penghitungan row weight dan melakukan normalized row weight. Perhitungan nilai kepentingan, kinerja dan tingkat harapan didapatkan dari hasil defuzifikasi pada metode fuzzy.

Technical response adalah cara untuk menyikapi kebutuhan penumpang stasiun yang didapatkan dari hasil brainstorming dengan pihak Stasiun Gambir. Relationship merupakan hubungan antara kebutuhan penumpang dengan technical response yang diberikan pihak Stasiun Gambir. Pada relationship ini digambarkan dengan hubungan kuat, sedang, lemah dan tidak berhubungan sama sekali. Masing-masing jenis hubungan memiliki nilai yang berbeda. Hubungan kuat ditandai dengan skor 9, hubungan sedang ditandai dengan skor tiga, hubungan lemah ditandai dengan skor 1 dan yang tidak memiliki hubungan ditandai dengan skor 0 . Berdasarkan hasil pada pengolahan data, dapat kita lihat bahwa terdapat beberapa hubungan yang terbentuk. 
Korelasi teknis ini digunakan untuk mengetahui korelasi antar masing - masing technical response yang ada. Masing - masing hubungan yang dimiliki oleh technical response masing masing berhubungan kuat. Dalam penyusunan technical matrix dibutuhkan nilai contribution. Nilai contribution ini menyatakan besarnya kontribusi dari technical response dalam memenuhi kebutuhan pelanggan. Rumah kualitas hasil metode QFD dapat dilihat pada Gambar 5.

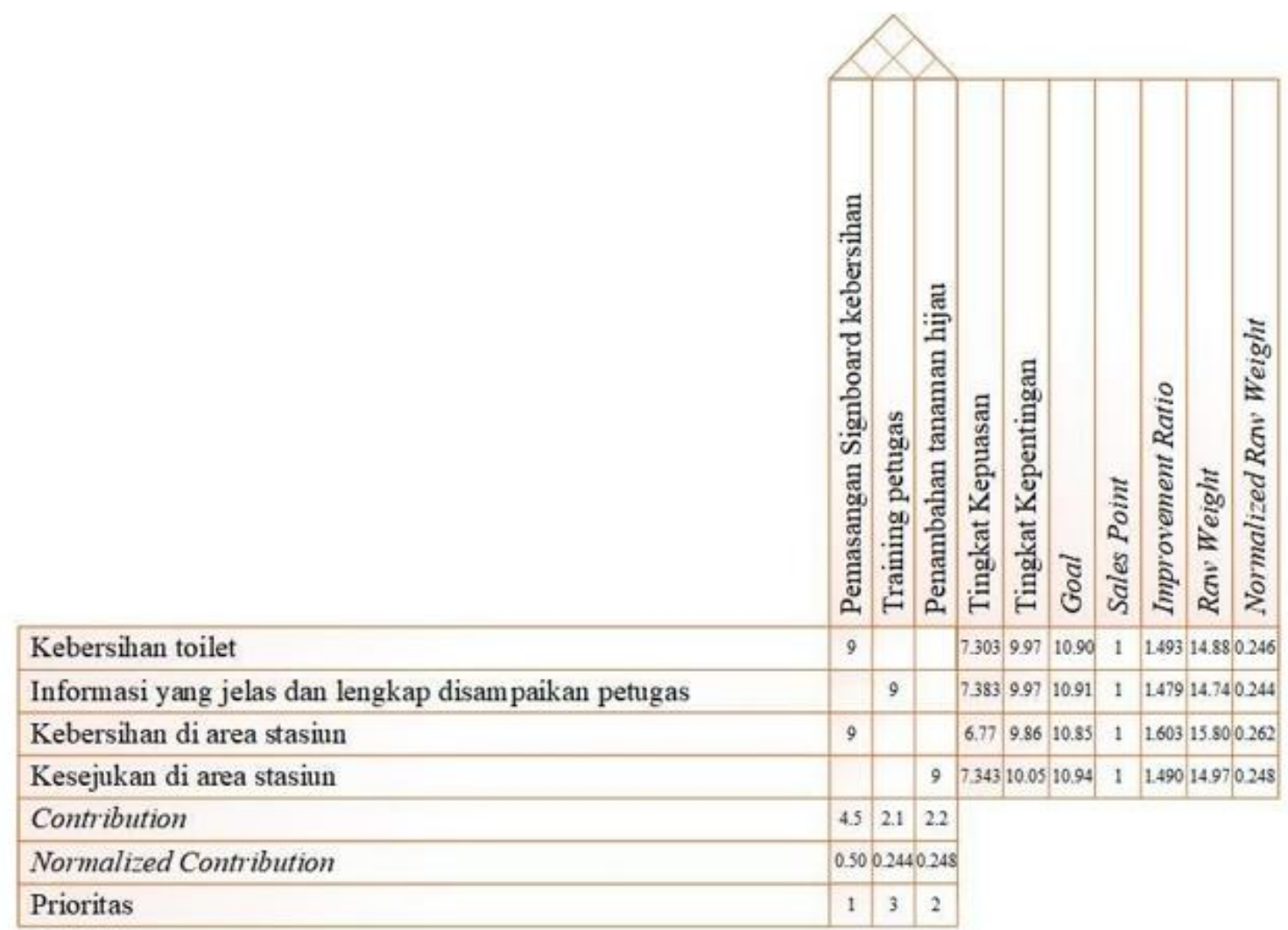

Gambar 5. Rumah kualitas layanan Stasiun Gambir

Rekapitulasi rekomendasi hasil metode $Q F D$ disajikan pada Tabel 4.

Tabel 4. Rekapitulasi rekomendasi perbaikan

\begin{tabular}{|c|c|c|c|c|}
\hline Prioritas & $\begin{array}{l}\text { Technical } \\
\text { Response }\end{array}$ & $\begin{array}{l}\text { Kebutuhan } \\
\text { Penumpang }\end{array}$ & $\begin{array}{l}\text { Kondisi } \\
\text { Sekarang }\end{array}$ & Rekomendasi \\
\hline 1 & $\begin{array}{l}\text { Membuat sign } \\
\text { board kebersihan }\end{array}$ & $\begin{array}{l}\text { Kebersihan toilet \& } \\
\text { Kebersihan area stasiun }\end{array}$ & $\begin{array}{l}\text { Tidak ada sign } \\
\text { board kebersihan } \\
\text { didalam toilet dan } \\
\text { area stasiun }\end{array}$ & $\begin{array}{l}\text { Membuat sign board } \\
\text { kebersihan di dalam } \\
\text { toilet \& area stasiun }\end{array}$ \\
\hline 2 & $\begin{array}{l}\text { Menerapkan } \\
\text { sistem reward and } \\
\text { punishment } \\
\text { petugas }\end{array}$ & $\begin{array}{l}\text { Informasi yang jelas } \\
\text { dan lengkap } \\
\text { disampaikan petugas }\end{array}$ & $\begin{array}{l}\text { Terjadi kesalahan } \\
\text { pada } \\
\text { penyampaian } \\
\text { informasi kepada } \\
\text { pelanggan stasiun }\end{array}$ & $\begin{array}{l}\text { Melakukan sistem } \\
\text { reward and } \\
\text { punishment petugas }\end{array}$ \\
\hline 3 & $\begin{array}{l}\text { Penambahan } \\
\text { tanaman hijau }\end{array}$ & Kesejukan di Stasiun & $\begin{array}{l}\text { Kurangnya } \\
\text { tanaman hijau }\end{array}$ & $\begin{array}{l}\text { Penambahan } \\
\text { tanaman hijau }\end{array}$ \\
\hline
\end{tabular}




\section{KESIMPULAN DAN SARAN}

Berdasarkan hasil penelitian mengenai analisis kualitas layanan Stasiun Gambir, maka dapat disimpulkan sebagai berikut:

a. Terdapat 23 atribut layanan yang mempengaruhi tingkat kepuasan penumpang di Stasiun Gambir.

b. Hasil metode $I P A$, terdapat 4 atribut layanan yang masuk ke dalam kuadran I untuk segera diperbaiki. Keempat atribut layanan tersebut adalah kebersihan toilet, informasi yang lengkap dan jelas disampaikan petugas, kebersihan di area stasiun dan kesejukan di area stasiun.

c. Hasil metode $Q F D$, terdapat usulan atau rekomendasi perbaikan yang didapat dari technical response yang bersumber dari hasil brainstorming dengan pihak Stasiun Gambir. Rekomendasi tersebut berupa pemasangan signboard untuk menjaga kebersihan, penambahan tanaman hijau di beberapa titik serta menerapkan sistem reward and punishment petugas

Berdasarkan penelitian yang telah dilakukan terdapat beberapa saran untuk Stasiun Gambir:

a. Pihak Stasiun Gambir hendaknya melakukan pemasangan signbord kebersihan di toilet dan di area stasiun agar kebersihan tetap terjaga.

b. Pihak Stasiun Gambir hendaknya menerapkan sistem reward and punishment petugas untuk mengurangi adanya kesalahan

c. dan untuk mengapresiasi petugas guna untuk meningkatkan kinerjanya.

d. Pihak Stasiun Gambir hendaknya memperbanyak tanaman hijau agar suasana stasiun sejuk dan asri.

Untuk penelitian selanjutnya diharapkan dapat mempertimbangkan dan mengembangkan atribut kualitas layanan lainnya.

\section{REFERENSI}

Akao, Y. (1988). Quality Function Deployment QFD, Integrating Customer Requirements into Product Design, Productivity Press, Portland, Oregon.

Amstrong, J., \& Preston, J. (2017). Capacity utilization and performance at railway stations. Journal of Rail Transport Planning \& Management, 7(3), 187-205.

Bakti, I.G.M.Y., Rakhmawati, T., Sumaedi, S., \& Damayanti, S. (2020). Railway commuter passenger' perceived service quality: Hedonic and utilitarian framework. Transportation Research Procedia, 48, 207-217.

Cascetta, E., \& Carteni, A. (2014). The hedonic value of railways terminals. A quantitative analysis of the impact of stations quality on travellers behaviour. Transportation Research Part A: Policy and Practice, 61, 41-52.

Deveci, M., Oner, S.C., Canitez, F., \& Oner, M. (2019). Evaluation of service quality in public bus transportation using interval-valued intuitionistic fuzzy QFD methodology, Research in Transportation Business \& Management, 33, 100387.

De Ona, J., De Ona, R., Eboli, L., \& Mazzulla, G. (2015). Heterogeneity in perceptions of service quality among groups of railway passengers. International Journal of Sustainable Transportation, 9(8), 612-626.

Eboli, L., Forciniti, C., \& Mazzulla, G. (2018). Spasial variation of the perceived transit service quality at rail stations. Transportation Research Part A: Policy and Practice, 114, 67-83.

Ghosh, P.G., Ojha, M.K., \& Geetika. (2017). Determining passenger satisfaction out of platform-based amenities: A study of Kanpur Central Railway Station. Transport Policy, 60, 108-118. 
Hair, J.F., Black, W.C., Babin, B.J., \& Anderson, R.E. (2010). Multivariate Data Analysis. 7th Edition, Pearson, New York.

Hundal, B.S., \& Kumar, V., 2015. Assessing the service quality of northern railway by using Servqual model. Pacific Business Review International, 8(2), 82-88.

Lai, W., \& Chen, C. (2011). Behavioral intention of public transit passenger - the role of service quality, perceived value, satisfaction and involvement. Transport Policy, 18(2), 318-325.

Liou, Y., \& Tsao, W.Y. (2010). A study on the service model of public transportation: Taiwan Railways vs. Taiwan High Speed Rail Corporation. International Journal of Service Science,1(2), 32-42.

Martilla, J., \& James, J. (1977). Importance Performance Analysis. Journal of Marketing, 41(1),77-79.

Maruvada, D. P., \& Bellamkonda, R. S. (2010). Analyzing the passenger service quality of the Indian railways using Railqual: Examining the applicability of fuzzy logic. International Journal of Innovation, Management and Technology, 1(5), 478-482.

Ojha, M.K. (2020). Quality of service delivery at railways platforms: A case of Allahabad junction railway station. Case Studies on Transport Policy, 8, 1087-1095.

Parasuraman, A., Zeithaml, V., \& L. L. Berry, L.L. (1986). SERVQUAL: A multiple-item scale for measuring customer perceptions of service quality. Journal of Retailing, 64(1), 12-40.

Sukwadi, R., Yang, C.C., \& Fan, L. (2012). Determining the priority of critical service attributes: An integrated model and an empirical case study in the higher education sector. Service Science, 4(4), 308-319.

Sukwadi, R., \& Jufina. (2015). Penentuan prioritas perbaikan kualitas layanan TransJakarta dengan menggunakan metode IPA-PGCV. Jurnal Rekayasa Sistem Industri, 4(2), 64-69.

Sukwadi, R., \& Teofilus, G. (2015), Behavioral intention penumpang KRL Commuter Line Jabodetabek. Jurnal Teknik Industri JATI, 10(2), 71-76.

Sukwadi, R., Yang, C.C., \& Benny. (2014). Integrasi fuzzy AHP-TOPSIS dalam evaluasi kualitas layanan elektronik rumah sakit. Jurnal Teknik Industri: Jurnal Keilmuan dan Aplikasi Teknik Industri, 16(1), 25-34.

Tannady, H. (2018). Mengkaji kepuasan pelanggan terhadap kualitas layanan e-commerce dengan menggunakan metode Importance Performance Analysis 3 Dimensi. Journal of Business \& Applied Management, 11(2), 116-238.

Wilujeng, F. R., Rembulan, G. D., Andreas, D., \& Tannady, H. (2019). Meningkatkan kepuasan pelanggan pada dua bisnis e-commerce terbesar di indonesia dengan menggunakan analisis Servqual dan IPA. SEMNASTEK-Seminar Nasional Sains dan Teknologi, hal 1-9. 